\title{
Factors Associated with Discontinuing Exclusive Breastfeeding among Mothers of Infants Aged 0-6 Months
}

\author{
Binita Dhakal,' Pratima Thapa,' \\ 'Department of Nursing, College of Medical Sciences, Bharatpur-10, Chitwan, Nepal.
}

\section{ABSTRACT}

\section{Introduction}

Knowing breastfeeding is one of the easiest and cost-effective ways to maintain a good child health, majority infants are not exclusively breastfed for the recommended 6 months of age. Thus, the aim of the study was to find out the factors associated with discontinuing exclusive breastfeeding (EBF) among mothers of infants' aged 0-6 months.

\section{Methods}

A analytical study design was used to find out the factors associated with discontinuing EBF among mothers of infants' aged 0-6 months in Nepal. A total of 380 mothers of infants whose child were 0-6 months old were selected using non-probability purposive sampling technique through online survey as people are advised to stay at home during the Covid-19 outbreak. Data was collected using structured questionnaire with interview technique.

\section{Results}

Study findings revealed that half $(50.5 \%)$ of the mothers exclusive breastfed their infants with mother's mean age being $27.39 \pm 3.64$ years. Discontinuation of EBF varied with mothers age, ethnicity, mother's educational level, initiation of breastfeeding and sources of information regarding $\mathrm{EBF}$ as newspaper/articles and relatives/friends/neighbors $(p=<0.005)$. The factors related to mother that are associated with discontinuation of EBF were found to be perceived insufficient milk, cesarean section delivery, jobholder mother $(p=<0.001)$ respectively.

\section{Conclusions}

Only half of respondents exclusively breastfed their infants for the recommended age in which only factors related to mother were significant with discontinuation of EBF rather than infants'. Findings of the study emphasizes on counselling the mothers regarding the benefits of EBF to both child and mother during hospital visits.

Keywords: Exclusive breastfeeding; factors; under 6 months; EBF.

Correspondence: Ms. Binita Dhakal, College of Medical Sciences, Bharatpur-10, Chitwan, Nepal. Email: bineetadhakal@gmail.com, Phone: +9779804219970. 


\section{INTRODUCTION}

World Health Organization (WHO) and United Nations Children's Fund (UNICEF) recommend giving infant only breast milk and no additional food, water or other fluids with the exception of medicine, vitamin or mineral drops for the first six months of life after birth. ${ }^{1}$

According to Global Breastfeeding Scorecard survey in 194 countries, Nepal was able to adopt exclusive breastfeeding practice above $60 \%$. ${ }^{2}$ The exclusive breastfeeding rate for 6 months age in Nepal was $66 \%$ in 2016. This comparison put Nepal in having higher exclusive breastfeeding rate. However, the condition is still not satisfactory ${ }^{3}$ because breast milk is best source of nourishment for infants containing antibodies that protect against some common childhood illnesses ${ }^{4}$ and gap has to be covered for better child health and reduce child mortality.

The objective of this study was to assess the factors associated with discontinuing exclusive breastfeeding among mothers of infants' aged 0-6 months.

\section{METHODS}

Analytical study design was used to find out the factors associated with discontinuing exclusive breastfeeding among mothers of infants' aged 0-6 months in Nepal. The required sample for this study was calculated using Cochran, 1977 formula for infinite population with a reference proportion of $34 \%{ }^{3}$ which was 380 by adding $10 \%$ non-response rate.

The data was collected through online survey from Nepali nationality who are residing in Nepal at that moment. As people are advised to stay at home during the Covid-19 outbreak, thus the researcher attempted to collect the data online. The study population for this study comprised of mothers of infants' aged
0-6 months of Nepalese nationality where nonprobability purposive sampling technique was be used for data collection. Structured questionnaire with interview technique was be used to assess the factors associated with nonexclusive breastfeeding among mothers under 6 months postpartum in Nepal. Ethical approval was taken from CMSTH-Institutional Review Committee (IRC), Bharatpur-10, Chitwan. Verbal consent was taken from the each respondent.

The data was coded and entered in EPI data 3.1 and exported into the IBM SPSS version 20 for analysis. Data was summarized using descriptive statistics such as frequency, percentage, mean and standard deviation. Chi square test was used to find out the association between exclusive breast feeding and selected variables at 0.05 level of significance.

\section{RESULTS}

Table 1. Socio-demographic Characteristics of the Respondents

\begin{tabular}{|l|l|l|}
\hline \multicolumn{1}{|c|}{ Variables } & Frequency & Percentage \\
\hline Mother's age \\
\hline $20-25$ years & 114 & 30.0 \\
\hline $26-30$ years & 195 & 51.3 \\
\hline 31 years and above & 71 & 18.7 \\
\hline
\end{tabular}

Mean age (in years) $\pm S D 27.39 \pm 3.64 ; \mathrm{Min}=20$, $\operatorname{Max}=37$

\begin{tabular}{|l|l|l|}
\hline $\begin{array}{l}\text { Mother's educational } \\
\text { level }\end{array}$ & & \\
\hline Secondary level & 16 & 4.2 \\
\hline Higher secondary & 100 & 26.3 \\
\hline Bachelor and above & 264 & 69.5 \\
\hline $\begin{array}{l}\text { Father's educational } \\
\text { level }\end{array}$ & & \\
\hline Secondary level & 33 & 8.7 \\
\hline Higher secondary & 84 & 22.1 \\
\hline Bachelor and above & 263 & 69.2 \\
\hline
\end{tabular}




\begin{tabular}{|c|c|c|}
\hline Place of residence & & \\
\hline Urban area & 306 & 80.5 \\
\hline Rural area & 74 & 19.5 \\
\hline \multicolumn{3}{|l|}{ Ethnicity } \\
\hline Dalit & 3 & 0.8 \\
\hline Janjati & 68 & 17.9 \\
\hline Madhesi & 5 & 1.3 \\
\hline Brahmin & 199 & 52.4 \\
\hline Chhetri & 102 & 26.8 \\
\hline Others & 3 & 0.8 \\
\hline \multicolumn{3}{|l|}{ Religion } \\
\hline Hindu & 360 & 94.7 \\
\hline Boudhha & 12 & 3.2 \\
\hline Muslim & 3 & 0.8 \\
\hline Christian & 4 & 1.1 \\
\hline Others & 1 & 0.3 \\
\hline \multicolumn{3}{|l|}{ Mother's occupation } \\
\hline Housewife & 178 & 46.8 \\
\hline Business & 45 & 11.8 \\
\hline Job & 148 & 38.9 \\
\hline Agriculture & 6 & 1.6 \\
\hline Others & 3 & 0.8 \\
\hline \multicolumn{3}{|l|}{ Family Type } \\
\hline Nuclear family & 138 & 36.3 \\
\hline Joint family & 236 & 62.1 \\
\hline Extended family & 6 & 1.6 \\
\hline
\end{tabular}

SD-standard deviation Min-minimum Max- maximum

Table 1 shows that out of 380 respondents, 30\% are aged $20-25$ years and $18.7 \%$ are aged 31 years and above. The mean age of the respondent was $27.39 \pm 3.64$. Regarding mother's and father's educational level $69.5 \%$ and $69.2 \%$ studied bachelor and above respectively whereas $4.2 \%$ and $8.7 \%$ studied till secondary level respectively. Regarding place of residence majority (80.5\%) resided in urban area. Regarding ethnicity more than half (52.4\%) were brahmin and $0.8 \%$ were dalit. Regarding religion majority (94.7\%) were hindu whereas $0.8 \%$ were muslim. Out of 380 respondents $46.8 \%$ of the mothers' were housewife and majority $(62.1 \%)$ of the families lived in joint family.

Table 2. Distribution of respondents according to child's characteristics

\begin{tabular}{|c|c|c|}
\hline Variables & Frequency & Percentage \\
\hline \multicolumn{3}{|l|}{ Child's age } \\
\hline Birth to 3 months & 176 & 46.3 \\
\hline $\begin{array}{l}\text { Above } 3 \text { months to } 6 \\
\text { months }\end{array}$ & 204 & 53.7 \\
\hline \multicolumn{3}{|l|}{$\begin{array}{l}\text { Mean age (in months) } \pm S D \\
3.62 \pm 1.70\end{array}$} \\
\hline \multicolumn{3}{|l|}{ Child's sex } \\
\hline Male & 226 & 59.5 \\
\hline Female & 154 & 40.5 \\
\hline \multicolumn{3}{|c|}{ Gestation age of the child at birth } \\
\hline Term (37 weeks ) & 325 & 85.5 \\
\hline Preterm (<37 weeks) & 55 & 14.5 \\
\hline
\end{tabular}

Child born with any congenital anomaly

\begin{tabular}{|l|l|l|}
\hline Yes & 10 & 2.6 \\
\hline No & 370 & 97.4 \\
\hline $\begin{array}{l}\text { If yes, which congenital } \\
\text { anomaly (n=10) }\end{array}$ & \\
\hline Club foot & 2 & 20 \\
\hline Congenital Heart disease & 2 & 20 \\
\hline Others & 6 & 60 \\
\hline Child admitted to hospital after delivery \\
\hline Yes & 48 & 12.6 \\
\hline No & 332 & 87.4 \\
\hline If yes, the cause for hospital admission (n=48) \\
\hline Birth asphyxia & 14 & 29.2 \\
\hline Jaundice & 3 & 6.2 \\
\hline Pneumonia & 3 & 6.2 \\
\hline Fever & 11 & 23 \\
\hline Others & 17 & 35.4 \\
\hline
\end{tabular}

SD-standard deviation Min-minimum Max- maximum

Table 2 shows that out of 380 respondents, $53.7 \%$ had child aged 3-6 months and $46.3 \%$ had child aged 0-3 months with 59.5\% male child and $40.5 \%$ having female child. 
Regarding gestation age of child at birth $85.5 \%$ babies were term and $14.5 \%$ babies were preterm. Regarding babies born with any congenital anomaly only $2.6 \%$ were born with congenital anomaly among which $20 \%$ each were club foot and congenital heart disease. Out of 380 children of the respondents $87.4 \%$ children were not admitted to hospital whereas $12.6 \%$ were admitted among which 35.4\% were due other causes most of which were breathing problems and transient tachypnea of newborn.

\begin{tabular}{|l|l|l|}
\hline $\begin{array}{l}\text { Table 3. Distribution of Respondents according to } \\
\text { Obstetric Characteristics }\end{array}$ & Frequency & Percentage \\
\hline Variables & & \\
\hline Frequency of ANC visit & 5 & 1.3 \\
\hline 1 time & 4 & 1.1 \\
\hline 2 times & 10 & 2.6 \\
\hline 3 times & 48 & 12.6 \\
\hline 4 times & 313 & 82.4 \\
\hline 4 times and above & & \\
\hline Parity during this child & 277 & 72.9 \\
\hline Primiparus & 103 & 27.1 \\
\hline Multiparous & & \\
\hline $\begin{array}{l}\text { Pregnancy related } \\
\text { condition }\end{array}$ & 184 & 48.4 \\
\hline No any & 308 & 81.1 \\
\hline Preeclampsia & 31 & 8.2 \\
\hline Eclampsia & 11 & 2.9 \\
\hline Others & 30 & 7.9 \\
\hline $\begin{array}{l}\text { Information obtained on exclusive breastfeeding } \\
\text { during ANC checkup }\end{array}$ & \\
\hline Yes & 196 & \\
\hline No & & \\
\hline breastfeeding & & \\
\hline
\end{tabular}

\begin{tabular}{|l|l|l|}
\hline Yes & 342 & 90 \\
\hline No & 38 & 10 \\
\hline $\begin{array}{l}\text { Source of information regarding exclusive } \\
\text { breastfeeding* (n=342) }\end{array}$ & \multicolumn{2}{l|}{} \\
\hline Health personnel & 171 & 45 \\
\hline Mass Media & 135 & 35.5 \\
\hline Newspaper/ Articles & 72 & 18.9 \\
\hline $\begin{array}{l}\text { Relatives/ friends/ } \\
\text { neighbors }\end{array}$ & 124 & 32.6 \\
\hline Books & 111 & 29.2 \\
\hline Others & 15 & 3.9 \\
\hline Delivery place & & \\
\hline Hospital & 379 & 99.7 \\
\hline Home & 1 & 0.3 \\
\hline Type of delivery & & \\
\hline Normal vaginal delivery & 161 & 42.4 \\
\hline Caesarean Section & 219 & 57.6 \\
\hline
\end{tabular}

* multiple response

Table 3 shows that out of 380 respondents, $82.4 \%$ of the respondents went ANC visits for more than 4 times whereas $1.1 \%$ of the respondents went for 2 ANC visits throughout their pregnancy. Regarding parity $72.9 \%$ respondents were primiparous whereas $27.1 \%$ were multiparous. Regarding pregnancy related condition majority $(81.1 \%)$ had no pregnancy related health issues whereas $2.9 \%$ had eclampsia. Regarding information on exclusive breastfeeding during ANC visit $48.4 \%$ said they received whereas $51.6 \%$ said they did not receive any. Out of 380 respondents majority (90\%) had heard about exclusive breastfeeding among which 35.5\% of the respondent's source of information was mass media. Regarding the place of delivery 99.7\% delivered at hospital and $0.3 \%$ delivered at home. Regarding the type of delivery $42.4 \%$ had normal vaginal delivery whereas $57.6 \%$ had caesarean section. 
Table 4. Distribution of Respondents according to Breast Feeding Practices

\begin{tabular}{|c|c|c|}
\hline Variables & Frequency & Percentage \\
\hline \multicolumn{3}{|c|}{ Initiation of breastfeeding after delivery } \\
\hline Within 1 hour & 137 & 36.1 \\
\hline Within 3 hours & 58 & 15.3 \\
\hline Within 6 hours & 25 & 6.6 \\
\hline Within 24 hours & 41 & 10.8 \\
\hline After 24 hours & 119 & 31.3 \\
\hline \multicolumn{3}{|c|}{ First feeding to child after birth } \\
\hline Breastmilk & 180 & 47.4 \\
\hline Honey & 3 & 0.8 \\
\hline Cow / Buffalo milk & 1 & 0.3 \\
\hline Formula milk & 196 & 51.6 \\
\hline
\end{tabular}

Cause for not giving breastfeed immediately after delivery* $(n=200)$

\begin{tabular}{|l|l|l|}
\hline $\begin{array}{l}\text { Perceived insufficient breast } \\
\text { milk }\end{array}$ & 85 & 22.4 \\
\hline Family suggestion & 1 & 0.3 \\
\hline Caesarean section & 119 & 31.3 \\
\hline Breast problem & 7 & 1.8 \\
\hline Others & 11 & 2.9 \\
\hline
\end{tabular}

* multiple response

Table 4 shows that out of 380 respondents, $36.1 \%$ initiated breastfeeding within 1 hour after delivery whereas $6.6 \%$ initiated within 6 hours. Regarding first feeding to the child after delivery $51.6 \%$ fed formula milk and $47.4 \%$ fed breastmilk. Regarding cause for not giving breastfeeding immediately after delivery $31.3 \%$ said due to caesarean section and $0.3 \%$ said due to family suggestion.
Table 5. Distribution of respondents according to Exclusive Breast Feeding

\begin{tabular}{|l|l|l|}
\hline Variables & Frequency & Percentage \\
\hline \multicolumn{2}{|l|}{ Exclusive breastfed to baby } \\
\hline Yes & 188 & 50.5 \\
\hline No & 192 & 49.5 \\
\hline
\end{tabular}

Table 5 shows that out of 380 respondents, $50.5 \%$ exclusively breastfed their child whereas $49.5 \%$ did not.

Table 6. Causes for discontinuation of Exclusive breast Feeding.

\begin{tabular}{|c|c|c|}
\hline Variables & Frequency & Percentage \\
\hline
\end{tabular}

Causes related to child for discontinuing exclusive breastfeeding* $(n=192)$

\begin{tabular}{|l|l|l|}
\hline Twins baby & 1 & 0.3 \\
\hline Sick baby & 1 & 0.3 \\
\hline Crying baby & 46 & 12.1 \\
\hline Others & 6 & 1.6 \\
\hline
\end{tabular}

Causes related to mother for discontinuing exclusive breastfeeding* $(n=192)$

\begin{tabular}{|l|l|l|}
\hline $\begin{array}{l}\text { Perceived insufficient breast } \\
\text { milk }\end{array}$ & 161 & 42.4 \\
\hline Caesarean section & 29 & 7.6 \\
\hline Job holder mother & 31 & 8.2 \\
\hline Lack of family support & 5 & 1.3 \\
\hline Lack of breastfeeding skills & 5 & 1.3 \\
\hline $\begin{array}{l}\text { Suggestion from relatives/ } \\
\text { neighbors/ friends }\end{array}$ & 7 & 1.8 \\
\hline
\end{tabular}

* multiple response

Table 6 shows that out of 192 respondents who did not exclusively breast fed their child, the majority $(42.4 \%)$ cause was related to mother as perceived insufficient breastmilk whereas $0.3 \%$ each was cause related to child as twins baby and sick baby. 


\begin{tabular}{|c|c|c|c|}
\hline \multirow[t]{2}{*}{ Variables } & \multicolumn{2}{|c|}{ Exclusive Breast Feeding } & \multirow[t]{2}{*}{$p$ - value } \\
\hline & $\begin{array}{c}\text { Yes } \\
\text { No. }(\%)\end{array}$ & $\begin{array}{l}\text { No } \\
\text { No. (\%) }\end{array}$ & \\
\hline \multicolumn{4}{|l|}{ Mother's age } \\
\hline $20-25$ years & $65(57)$ & $49(43)$ & 0.004 \\
\hline $26-30$ years & $100(51.3)$ & $95(48.7)$ & \\
\hline Above 30 years & $23(32.4)$ & $48(67.6)$ & \\
\hline \multicolumn{4}{|l|}{ Ethnicity } \\
\hline Janjati & $33(48.5)$ & $35(51.5)$ & 0.034 \\
\hline Brahmin & $92(46.2)$ & $107(53.8)$ & \\
\hline Chhetri & $53(52)$ & $49(48)$ & \\
\hline Others & $10(90.9)$ & $1(9.1)$ & \\
\hline \multicolumn{4}{|l|}{ Mother's educational level } \\
\hline Secondary level & $11(68.8)$ & $5(31.2)$ & 0.015 \\
\hline Higher secondary level & $59(59)$ & $41(41)$ & \\
\hline Bachelor and above & $118(44.7)$ & $146(55.3)$ & \\
\hline \multicolumn{4}{|c|}{ Initiation of breastfeeding after delivery } \\
\hline Within 1 hour & $81(59.1)$ & $56(40.9)$ & 0.006 \\
\hline In 3 hours & $28(48.3)$ & $30(51.7)$ & \\
\hline In 6 hours & $14(56)$ & $11(44)$ & \\
\hline Within 24 hours & $22(53.7)$ & $19(46.3)$ & \\
\hline After 24 hours & $43(36.1)$ & $76(63.9)$ & \\
\hline \multicolumn{4}{|c|}{$\begin{array}{l}\text { Cause for not giving breastfeed immediately after delivery* } \\
(n=200)\end{array}$} \\
\hline Perceived insufficient breastmilk & $29(34.1)$ & $56(65.9)$ & 0.001 \\
\hline \multicolumn{4}{|c|}{ Source of information on exclusive breast feeding* $(n=342)$} \\
\hline Newspaper/Articles & $28(38.9)$ & $44(61.1)$ & 0.046 \\
\hline Relatives/Neighbors/Friends & $51(41.1)$ & $73(58.9)$ & 0.024 \\
\hline \multicolumn{4}{|c|}{$\begin{array}{l}\text { Causes related to mother for discontinuing exclusive } \\
\text { breastfeeding }(n=192)\end{array}$} \\
\hline Perceived Insufficient breastmilk & $6(3.7)$ & $155(96.3)$ & $<0.001$ \\
\hline Caesarean section & $1(3.4)$ & $28(96.6)$ & $<0.001$ \\
\hline Job holder mother & $3(9.7)$ & $28(90.3)$ & $<0.001$ \\
\hline Lack of breastfeeding skills & $0(0)$ & $5(100)$ & 0.026 \\
\hline
\end{tabular}


Table 7 shows that there is statistically significant association between discontinuing exclusive breast feeding and mother's age $(\mathrm{p}=0.004)$, ethnicity $(p=0.034)$, mother's educational level $(\mathrm{p}=0.015)$, time of initiation of breastfeeding after delivery $(p=0.006)$ and cause for not giving breastmilk immediately after delivery due to perceived insufficient breast milk $(p=0.001)$. There is also statistically significant association between discontinuing exclusive breast feeding and the source of information on exclusive breastfeeding as newspaper/articles $(p=0.046)$ and relatives/neighbors/friends $(p=0.024)$. Regarding the association between discontinuing exclusive breastfeed and its causes related to mother there was statistically significant association to perceived insufficient breast milk $(p=<0.001)$, caesarean section $(p=<0.001)$, job holder mother $(p=<0.001)$ and lack of breastfeeding skills ( $\mathrm{p}=0.026)$.

\section{DISCUSSION}

In this study, mean age of the respondent (mother) was $27.39 \pm 3.64$ years and that of child was $3.62 \pm 1.70$ months which was similar to the mean age of mothers $25.38 \pm 4.14$ years, but not to that of infants which was $9.98 \pm 2.26$ months because this study only included infants under 6 months of age. ${ }^{5}$ In the present study, maternal education was above secondary level whereas contrary findings were present in a similar study where almost half (47.5\%) had above primary level education. This difference might be due to the data collection technique in the current study via online where only educated people with internet access got chances to participate. ${ }^{6}$

Mother's occupation of almost half $(46.8 \%)$ was housewife where similar results has been noted in a study of $53.5 \%$ mothers being a housewife. ${ }^{7}$ The normal vaginal delivery mothers' had during this current child in this study was $42.4 \%$ whereas higher incidence was found in a study where normal vaginal delivery was $73.38 \%$. This difference is due to increase in the rate of caesarean section deliveries in Nepal over the time. $^{8}$

According to the data of present study, the prevalence of exclusive feeding until 6 months is $50.5 \%$ which is lower to the national data of 2016 that is $66 \%$ at 6 months. ${ }^{3}$ The decrease in the prevalence might be due to the current study's method of data collection via online due to COVID pandemic where respondents' who had access to internet could only participate and those not having were excluded which can also be seen in the data as respondents level of education was high and area of residence was mostly $(80.5 \%)$ urban area.

In the present study, the discontinuation of EBF was significantly associated with mother's age and mother's educational level which is in accordance in a study done in India. ${ }^{6}$

The timing of initiation of breastmilk was significantly associated with discontinuation of EBF where the late the initiation the more discontinuation of exclusive breastfeeding was found in the present study which was in accordance with a study in Ethopia where not initiating breastfeeding early (within 1 hour) was one of the variable associated with cessation of EBF 7 this similarity is due to evidences supporting the increase in the likelihood of exclusive breastfeeding for one to four months of life as well as the overall duration of breastfeeding if initiated early breastfeeding. ${ }^{9}$

In a similar study in Taiwan the factors associated with cessation of exclusive breast feeding was perceived low milk quantity, Caesarean birth, lack of tertiary education of mother and mother's return to work ${ }^{10}$ which was similar with the current study where perceived insufficient milk, job holder mother and caesarean section delivery was significantly associated with discontinuation of EBF but mother's lack of tertiary education was not the factor in the present study which might be due to not sufficient (51.6\%) antenatal 
counselling regarding benefits of EBF despite of having higher degrees of education.

\section{CONCLUSIONS}

The findings of this study revealed that prevalence of exclusive breast feeding was $50.5 \%$ which was lower than the national data and national/international recommendation on breastfeeding. Variables like mother's age, educational level, ethnicity, initiation of breastfeeding after delivery, source of information on breastfeeding as newspaper/ articles, friends/relatives/neighbors were significantly associated with discontinuation

\section{REFERENCES}

1. UNICEF, WHO. Capture the Moment - Early initiation of breastfeeding: The best start for every newborn. New York: UNICEF; 2018. [Link]

2. WHO \& UNICEF. Tracking Progress for Breastfeeding Policies and Programmes. 2017. [Link]

3. Ministry of Health - MOH/Nepal, New ERA/Nepal, and ICF. 2017. Nepal Demographic and Health Survey 2016. Kathmandu, Nepal: MOH/Nepal, New ERA/Nepal, and ICF. [Link]

4. WHO. Essential nutrition actions: improving maternal, newborn, infant and young child health and nutrition. 2013. [Link]

5. Dharel D, Dhungana R, Basnet S, Gautam S, Dhungana A, Dudani R, et al. Breastfeeding practices within the first six months of age in mid-western and eastern regions of Nepal: a health facility-based cross-sectional study. BMC Pregnancy and Childbirth (2020) 20:59 [Link] of EBF. The factors related to mother where perceived insufficient milk, cesarean section delivery, job holder mother and lack of breastfeeding skills were found out to be associated with discontinuation of EBF. It is suggested the exclusive breastfeeding can be increased and promoted through breastfeeding education or training of mothers' knowledge, awareness and practices especially during antenatal checkup and followed up during postnatal checkup and vaccination of their babies.

6. Nishimura H, Krupp K, Gowda S, Srinivas V, Arun A, Madhivanan P. Determinants of exclusive breastfeeding in rural South India. International Breastfeeding Journal. (2018) 13:40. [Link]

7. Kelkay B, Kindalem E, Tagele E, Moges Y. Cessation of Exclusive Breastfeeding and Determining Factors at the University of Gondar Comprehensive Specialized Hospital, Northwest Ethiopia. International Journal of Pediatrics. 2020;8431953, 1-9. [Link]

8. Bhandari A K. C, Dhungel B, Rahman M. Trends and correlates of cesarean section rates over two decades in Nepal. BMC Pregnancy and Childbirth. 2020; 20:763. [Link]

9. WHO. Early initiation of breastfeeding to promote exclusive breastfeeding. 11 February 2019 09:29 CET [Link]

10. Chang P, Li S, Yang H, Wang L, Weng C, Chen K, et al. Factors associated with cessation of exclusive breastfeeding at 1 and 2 months postpartum in Taiwan. International Breastfeeding Journal. 2019;14:18. [Link]

Citation: Dhakal B, Thapa P. Factors Associated with Discontinuing Exclusive Breastfeeding Among Mothers of Infants' Aged 0-6 Months in Nepal. CMS Nepal. 2021 ; 17(3); 257-64. 